\title{
ATENÇÃO À SAÚDE E SURDEZ: DESAFIOS PARA IMPLANTAÇÃO DA REDE DE CUIDADOS À PESSOA COM DEFICIÊNCIA
}

\author{
Deafness and health care: challenges to the implementation of the Care Network for the \\ Disabled

\section{Atención a la salud y la sordera: desafios de la implantación de la red de cuidados a la persona con discapacidad}

\author{
Juliana Donato Nóbrega \\ Universidade Federal do Ceará - UFC - Fortaleza (CE) - Brasil
}

Marilene Calderaro Munguba

Universidade de Fortaleza - UNIFOR - Fortaleza (CE) - Brasil

Ricardo José Soares Pontes

Universidade Federal do Ceará - UFC - Fortaleza (CE) - Brasil

\section{RESUMO}

Objetivo: Conhecer a assistência à saúde prestada às pessoas surdas, usuárias da Língua Brasileira de Sinais (Libras), a partir da sua perspectiva, com vistas a refletir sobre a inclusão de ações na Rede de Cuidados à Pessoa com Deficiência. Métodos: Estudo de abordagem qualitativa, realizado em 2010, com participação de 15 surdos adultos, usuários da Libras. Foram aplicadas as técnicas de grupo focal e entrevista aberta, com tradução simultânea entre a Língua Brasileira de Sinais e o português. As informações coletadas foram submetidas à análise temática. Resultados: $\mathrm{O}$ estudo evidenciou três categorias temáticas: barreiras nos serviços de saúde; atitudes para minimizar as barreiras de comunicação; e, sugestões para melhoria da assistência nos serviços de saúde. Essas informações podem interferir na assistência integral e humanizada à saúde. Em razão das dificuldades, surdos e profissionais de saúde recorrem a distintas estratégias para viabilizar o atendimento. Conclusão: O estudo possibilitou conhecer as peculiaridades da assistência à saúde às pessoas surdas, usuárias da língua de sinais, percebendo-se desafios durante o atendimento em virtude de uma comunicação restrita, de forma que a língua de sinais possa ser um dos caminhos para uma efetiva comunicação com esses usuários nos serviços de saúde.

Descritores: Surdez; Pessoas com Deficiência; Linguagem de Sinais; Barreiras de Comunicação; Atenção à Saúde; Saúde Pública.

\section{ABSTRACT}

Objective: To assess the health care provided to deaf people who use the Brazilian sign language (Libras), from their own perspective, aiming to reflect on the inclusion of actions into the Care Network for the Disabled. Methods: Study with a qualitative approach, conducted in 2010, with participation of fifteen deaf adults who use Libras. The techniques employed were focus group and open interview with simultaneous translation from the Brazilian Sign Language into Portuguese. Results: This study evidenced three thematic categories: barriers within the health services; attitudes to minimize communication barriers; and suggestions for improving health care delivery. This information may interfere with comprehensive and humanized health care. As a result of the difficulties, deaf people and health professionals resort to different strategies to enable care. Conclusion: The study made it possible to know the peculiarities of health care for deaf people, users of sign language, evidencing challenges during care delivery due to a restricted communication, so that sign language can be one of the ways for effective communication with these users in health services.

Descriptors: Deafness; Disabled Persons; Sign Language; Communication Barriers; Health Care; Public Health. 


\section{RESUMEN}

Objetivo: Conocer la asistencia de salud de personas sordas usuarias de la Lengua Brasileña de Señales (Libras) desde su perspectiva para reflexionar sobre la inclusión de las acciones de la Red de Cuidados a la persona con discapacidad. Métodos: Estudio de abordaje cualitativo realizado en 2010 con 15 sordos adultos y usuarios de Libras. Fueron aplicadas las técnicas de grupo focal y entrevista abierta con la traducción simultánea de la Lengua Brasileña de Señales para el portugués. Las informaciones recogidas fueron sometidas al análisis temático. Resultados: El estudio evidenció tres categorías temáticas: barreras de los servicios de salud; actitudes para disminuir las barreras de comunicación; y sugerencias para la mejoría de la asistencia de los servicios de salud. Esas informaciones pueden influir en la asistencia integral y humanizada de la salud. A causa de las dificultades los sordos y los profesionales sanitarios recurren a distintas estrategias para hacer la atención viable. Conclusión: El estudio ha posibilitado el conocimiento de las peculiaridades de la asistencia a la salud de personas sordas, usuarias de la lengua de señales percibiéndose los desafios durante la atención debido una comunicación restricta de manera que la lengua de señales puede ser uno de los caminos para una comunicación efectiva con los usuarios de los servicios de salud.

Descriptores: Sordera; Personas con Discapacidad; Lenguaje de Signos; Barreras de Comunicación; Atención a la Salud; Salud Pública.

\section{INTRODUÇÃO}

A Rede de Atenção à Saúde constitui um modo de organizar integralmente ações e serviços de saúde, de densidades tecnológicas distintas, com vistas à melhoria do acesso, integralidade do cuidado, efetividade das ações e eficiência econômica ${ }^{(1)}$.

A Rede de Cuidados à Pessoa com Deficiência (RCPD), instituída pela Portaria no 793, de 24 de abril de 2012 (2), é uma rede prioritária a ser implantada nas diversas regiões de saúde do país. O cuidado à saúde humanizado, integral e centrado nas necessidades das pessoas, portanto, diversificado em suas estratégias, desponta como diretriz para o funcionamento dessa rede ${ }^{(2)}$. Em consonância com a lógica instituída por essa portaria, ofertar serviços como base nas necessidades da população assistida e do território sanitário é um atributo fundamental para o funcionamento da rede de cuidado ${ }^{(1)}$. Identificar as pessoas com deficiência e suas necessidades é imperativo para compor um trabalho na lógica das redes de atenção.

O recenseamento estatístico da população brasileira, realizada pelo Instituto Brasileiro de Geografia e Estatística (IBGE), fornece indícios do quantitativo de pessoas com deficiência. O Censo de 2010 estimou 45 milhões de pessoas com deficiência, entre as quais nove milhões com deficiência auditiva e dois milhões com grau severo de problema de audição( ${ }^{(3)}$. Nesse universo, supõem-se a existência de surdos sinalizantes, aqueles que utilizam a Língua Brasileira de Sinais (Libras) como meio de expressão de ideias, sentimentos e valores, e interpretam o mundo sobretudo pela via visual de comunicação. A condição linguística das pessoas surdas lhes impõe desafios diários para acessar os serviços de saúde, haja vista o fato de se comunicarem por uma língua visuomotora e os serviços serem ofertados, quase que exclusivamente, em uma língua auditivo-oral. A diferença linguística cultural entre o português e a Libras demarca uma fronteira importante na assistência à saúde das pessoas surdas, a qual necessita ser investigada, uma vez que podem ensejar barreiras na prestação do cuidado em saúde. Segundo o Modelo Social da Incapacidade, as condições do entorno e as barreiras de participação também são causadoras das deficiências e incapacidade. Nesse modelo, embora considerada consequência das deficiências, não está mais no centro da discussão ${ }^{(4)}$. $\mathrm{O}$ novo modelo proposto para organizar as ações e serviços de saúde às pessoas com deficiência deve considerar não apenas questões que envolvam as limitações funcionais, mas também as condições do entorno e as barreiras, ou entraves.

A Rede de Cuidados à Pessoa com Deficiência constitui-se modelo de atenção voltado à população que expressa algum impedimento orgânico, ou funcional, de natureza física, sensorial e intelectual. Essa classificação inclui pessoas com deficiências motora, visual, auditiva, intelectual, ostomias e com múltiplas deficiências.

A portaria instituidora dessa Rede é oriunda do Plano Nacional dos Direitos da Pessoa com Deficiência (Plano Nacional Viver sem Limites) ${ }^{(5)}$, que define ações inclusivas no âmbito de educação, trabalho, acessibilidade e saúde. Na Saúde, a implantação da rede de atenção visa qualificar a atenção à pessoa com deficiência por meio da organização de uma rede de cuidados integrais no âmbito do Sistema Único de Saúde (SUS ${ }^{(2)}$. Com efeito, a rede funcionará mediante a interação de seus elementos constitutivos: população e território sanitário definidos, estrutura operacional (composta por pontos de atenção de densidades tecnológicas distintas que oferta serviços de saúde) e sistema lógico, fundamento de seu funcionamento ${ }^{(1,2)}$.

A RCPD deve possuir uma estrutura operacional ${ }^{(2)}$ organizada com apoio em três componentes especificamente, os quais devem se articular para prestar os cuidados à saúde: Atenção Básica, compreendida pelas Unidades Básicas de Saúde, abrangendo os serviços do Núcleo de Apoio à Saúde da Família (NASF) e da Atenção Odontológica; Atenção Especializada em Reabilitação, que agrega, como pontos de atenção, os estabelecimentos de saúde habilitados em apenas um tipo de Serviço de Reabilitação, Centros Especializados em Reabilitação (CER) e os Centros de Especialidades Odontológicas (CEO); e a Atenção Hospitalar e de Urgência e Emergência. Os três componentes exprimem pontos de atenção estratégicos para conformação dessa rede, devendo ser complementados por outros pontos a depender das necessidades de saúde dos usuários. 
Quatro fases foram definidas para implantação da $\mathrm{RCPD}^{(2)}$ : a primeira diz respeito ao diagnóstico e desenho regional da rede, que inclui a elaboração e a pactuação do desenho da rede e dos planos de ação regional e municipal; a segunda fase trata da adesão à rede, com a instituição de Grupo Condutor Estadual e a homologação da região inicial de implementação da RCPD; a terceira versa sobre a contratualização dos pontos de atenção pelo ente responsável, que ocorrerá após a elaboração do desenho municipal, e em observância à responsabilidade solidária para com a rede regional; já a quarta fase cuida da implantação e acompanhamento das ações de atenção definidas na RCPD pelo Grupo Condutor Estadual.

No ano de 2012, o Estado do Ceará iniciou o debate para a organização da RCPD. Nesse período, o Grupo Condutor Estadual coordenou, acompanhou e assessorou a elaboração de 16 planos regionais que compuseram o Plano Estadual de Estruturação da Rede de Cuidados à Pessoa com Deficiência 2013-2016(6). No âmbito das regiões de saúde, de maneira geral, os gestores e assessores técnicos municipais e estaduais discutiram, na Comissão Intergestores Regional (CIR), o desenho regional das redes e pactuaram os pontos de atenção para oferta dos serviços. Após discussão, os planos foram encaminhados ao Grupo Condutor Estadual para análise, e, quando aprovados, foram homologados na Comissão Intergestores Bipartite (CIB) e enviados ao Ministério da Saúde para avaliação dos custos e do possível financiamento.

No período de 2013 a 2016, foram previstas no Plano Estadual a implantação de 16 redes temáticas, com 39 Centros Especializados em Reabilitação (CER). A cada ano, foi estipulada a implantação de quatro redes ${ }^{(6)}$. Após a intensa elaboração do desenho da rede e da pactuação dos pontos de atenção entre gestores, três CER, dos 39 previstos no plano, encontram-se em fase de construção no Ceará (em Tauá, Juazeiro do Norte e Eusébio). Outros três equipamentos foram habilitados para prestação de cuidados em dois tipos de deficiências, e privilegiam a atenção especializada à deficiência auditiva, sendo um CER II em Sobral e dois CER II em Fortaleza.

Observou-se, na elaboração da RCPD, um esforço coletivo dos gestores e técnicos, das 22 regiões de saúde, para desenhar e elaborar uma proposta de estruturação da RCPD no estado, centrada na construção de Centros de Reabilitação que, na prática, não se concretizou e precisa ser repensada.

A Lei Brasileira de Inclusão da Pessoa com Deficiência, $n^{\circ} 13.146 / 2015^{(7)}$, assegura à participação das pessoas com deficiência na elaboração de políticas a elas destinadas. Nesse sentido, estudos que enfoquem a perspectiva dos usuários com deficiência sobre seu próprio processo de cuidado devem ser incentivados.

O estudo é relevante, pois problematiza experiências vivenciadas pelos próprios surdos nos serviços de saúde, possibilitando que informações advindas da pesquisa suscitem discussões sobre as especificidades desse atendimento e sirva de meio para repensar as práticas envolvidas no cuidado à saúde e nortear o planejamento de ações na RCPD, com vistas à melhoria da prestação de serviços para esses usuários e apoiar a organização e operacionalização da RCPD.

Portanto, objetiva-se conhecer a assistência à saúde prestada às pessoas surdas, usuárias da Língua Brasileira de Sinais (Libras), a partir da sua perspectiva, com vistas a refletir sobre a inclusão de ações na Rede de Cuidados à Pessoa com Deficiência.

\section{MÉTODOS}

Este estudo, de abordagem qualitativa ${ }^{(8,9)}$, foi realizado no município de Fortaleza, cidade localizada no Nordeste do Brasil, com o intuito de conhecer as experiências vivenciadas pelas pessoas surdas nos serviços de saúde, e, a partir daí, refletir sobre a assistência a essas pessoas no contexto das redes de atenção.

O setor de saúde tradicionalmente reconhece a opinião dos especialistas e profissionais como relevantes para o planejamento, organização e avaliação dos serviços. Os estudos de abordagem qualitativa diferem da tradição, ao considerar a existência de múltiplos pontos de vista para compreender o fenômeno em estudo ${ }^{(8)}$. Nesse sentido, as experiências dos usuários - e, nesse contexto dos usuários surdos - são de elevada importância, assim como a de outros agentes que compõem o serviço, para compreensão do fenômeno sob exame.

O campo da pesquisa, ocorrida em 2010, foi uma instituição pública vinculada à Secretaria de Educação do Estado, situada na cidade de Fortaleza, Ceará. A instituição tinha como objetivo prestar serviços diversos aos surdos e componentes seus familiares, tais como: promover cursos de Libras e outros cursos de formação, disseminar programas e eventos relacionados às temáticas da surdez; realizar orientação familiar e prestar serviços especializados voltados à aprendizagem das pessoas surdas. Nesse espaço, os surdos se reuniam com frequência para discutir e trocar experiências sobre os assuntos diversos ligados ao cotidiano da comunidade surda, sendo, portanto, um espaço potente para se debater e compreender as experiências dos surdos quando buscam os serviços de saúde.

Com efeito, os informantes foram escolhidos pela sua relevância para a questão da pesquisa ${ }^{(9)}$. O critério de inclusão foi ser surdo, maior de idade e participar das atividades da instituição. Participaram 15 surdos, sendo nove professores de Libras e seis alunos, estudantes do curso pré-vestibular, de ambos os sexos, com idade variando de 18 a 47 anos. Em relação à escolaridade dos professores, o menor nível referido foi superior incompleto, havendo surdo com registro de uma graduação ou cursando segunda graduação ou pós-graduação. Todos afirmaram comunicar-se no dia a dia com Libras.

O primeiro contato com o grupo de professores ocorreu na reunião que realizavam semanalmente. Mediada por um intérprete, houve a apresentação de uma das pesquisadoras, que explicou os objetivos e a metodologia da investigação. Em 
diálogo com o grupo, foi sugerido pelos próprios surdos que houvesse uma conversa também com os alunos do curso de prévestibular. Ao término da exposição, foi marcada a data para realização do primeiro grupo focal, a ocorrer na própria instituição consoante sugerido pelos próprios surdos.

Como técnicas de produção do material empírico, recorreu-se ao grupo focal e à entrevista aberta ${ }^{(8)}$, com traduçãointerpretação simultânea de Libras para português, e vice-versa, por intérpretes. O grupo focal ocorreu em quatro sessões e objetivou compreender as experiências dos participantes na interação grupal, o acesso às opiniões, seus confrontos e concordância. Duas sessões ocorreram com professores que ministram curso de Libras na instituição do campo de pesquisa, e outras duas com alunos de curso pré-vestibular que estudam nesse estabelecimento. O roteiro adotado para o grupo focal compreendeu as seguintes perguntas norteadoras: Como é para você (s) ser surdo? Como é o dia a dia de uma pessoa surda? As indagações que surgiram como desdobramento das perguntas norteadoras foram: Como ocorre o acesso de vocês aos serviços de saúde, educação, financeiro e outro? Que sugestões vocês dariam para melhorar a comunicação no serviço de saúde, serviço financeiro, nos serviços em geral?

A entrevista individual foi realizada em complementação ao grupo focal para melhor compreensão do objeto investigado e visou o aprofundamento de questões apontadas nos grupos. Nesse momento, participaram cinco surdos, identificados como bons informantes-chave, aqueles que têm conhecimentos sobre assunto abordado e facilidade para expressá-lo ${ }^{(10)}$.

Os materiais empíricos produzidos foram registrados em vídeo e áudio, e os relatos foram transcritos, submetidos à leitura flutuante para impregnação do sentido e analisados segundo a análise temática ${ }^{(11)}$. Nessa fase, houve a identificação de temas centrais, categorias analíticas e empíricas que compuseram a rede de significados da pesquisa. Constituíram-se, então, as seguintes categorias: a) Barreiras nos serviços de saúde; b) Atitudes para minimizar as barreiras de comunicação; e c) Sugestões para melhoria da assistência nos serviços de saúde.

A pesquisa foi aprovada pelo Comitê de Ética em Pesquisa da Universidade Federal do Ceará - COMEPE conforme o Parecer n 324/09, de acordo com as normas da Resolução 196/96 do Conselho Nacional de Saúde, que determina a ética em pesquisa envolvendo seres humanos, estando também em concordância com a Resolução 466/12(12,13).

Para identificar os relatos dos entrevistados e garantir seu anonimato, utilizou-se a letra inicial da palavra surdo (S) seguida do número de acontecimentos das entrevistas (S1, S2, S3, sucessivamente).

\section{RESULTADOS E DISCUSSÃO}

$\mathrm{Na}$ análise das informações produzidas na pesquisa, núcleos de sentido foram identificados e classificados como categorias, constituindo os temas centrais que compuseram a rede de significados do estudo. Neste espaço serão expressas e discutidas três categorias temáticas que emergiram do estudo: Barreiras nos serviços de saúde; Atitudes para minimizar as barreiras de comunicação; e, Sugestões para melhoria da assistência nos serviços de saúde.

\section{Barreiras nos serviços de saúde}

Esta categoria aborda as barreiras encontradas pelos surdos nos serviços de saúde, destacando os entraves comunicativos entre os profissionais de saúde ouvintes e as pessoas surdas que buscam atendimento.

O fazer em saúde, por envolver aspectos relacionais, exige práticas de cuidados que considerem as habilidades de comunicação interpessoal. As dificuldades de comunicação e informação entre profissionais que prestam assistência e usuários que buscam os serviços de saúde podem comprometer o cuidado, em razão da dificuldade de entendimento mútuo, configurar, assim, falha no atendimento humanizado e inclusivo. Os obstáculos vivenciados se tornam ainda mais preocupantes quando uma comunicação inadequada pode comprometer o diagnóstico dos problemas de saúde e o tratamento do paciente ${ }^{(14-16)}$.

“[...] às vezes eu sentia uma dor, algum problema, ou estava vomitando, ai eu resolvia ir ao médico [...] eu explicava que estava evacuando demais, e ele queria me mandar tomar soro. Ficava três horas lá tomando soro e o médico nem atendia direito. Eu ia para casa e continuava de novo com dor de barriga, passando mal. Novamente fui ao médico e a mesma coisa, só dava o soro, voltava para casa. [...]. O médico não entendia que eu estava evacuando, que eu estava com dor de barriga e que estava doente, era muito difícil a comunicação, precisava de um intérprete. Minha mãe foi e explicou, pronto, ai me deram o remédio, tomei e sarei, mas sozinho era só na base do soro" (S8).

"[...] eu não conseguia explicar o que eu estava sentindo e nem entender o que o dentista estava falando que tinha que fazer. Todo mundo olhando para mim, eu morri de vergonha, eu não sabia como fazer. Era uma coisa tão simples e era só tirar e fazer uma limpeza no dente, ai eu peguei e anotei para ele. Ele não acreditava, eu fiquei morrendo de medo. [...] O intérprete foi e explicou para o dentista do que se tratava a consulta, que era só obturar e só fazer uma limpeza, mas o dentista pensou que era para arrancar o dente [...] a gente tem muita dificuldade” (S2).

Somente pela comunicação efetiva, o profissional poderá compreender o que paciente expressa e, desse modo, ajudá-lo a reconhecer e enfrentar o processo de adoecimento e de saúde ${ }^{(17,18)}$. Ao término da consulta, entretanto, alguns pacientes não compreendem o seu problema, tampouco os motivos que levaram à indicação do uso da medicação administrada ${ }^{(19)}$. 
No dia a dia, a realidade confirma a escassez de profissionais de saúde que se comunicam adequadamente com as pessoas surdas. Poucos conhecem a língua de sinais e as peculiaridades da cultura surda, e um quantitativo ainda menor se comunica por essa língua.

Pesquisa estrangeira identificou o preparo insuficiente de um grande número de médicos para atenderem surdos que se comunicam, principalmente, pela língua de sinais, e o pouco conhecimento dos profissionais sobre a surdez e a respeito das maneiras distintas de comunicação dos surdos ${ }^{(15)}$. A ocorrência desses fatos se relaciona à lacuna na formação dos estudantes de Medicina em relação às competências e habilidades que facilitam a comunicação com o paciente surdo, ou com perda auditiva $^{(20)}$. De igual modo, ocorre com os demais profissionais da área da saúde, sendo esse fato apontado como motivo que enseja importante entrave no atendimento dessas pessoas ${ }^{(17,21)}$.

Incluir informações nos cursos de graduação quanto à perda de audição, comunicação médico-paciente e técnicas para melhorar a capacidade de ouvir e aprender a história desses pacientes torna-se fundamental nos cursos de Medicina ${ }^{(20)}$ e nos demais programas de graduação da área de saúde. De igual modo, devem ser abordadas as distintas concepções de surdez e de pessoa surda, que incluem suas dimensões fisiológicas, simbólicas e culturais ${ }^{(22)}$. A capacitação em competências culturais para os profissionais de saúde também pode contribuir para favorecer o acesso dos surdos aos serviços ${ }^{(23)}$.

Pautada no projeto clínico-hegemônico-patológico da deficiência, a formação acadêmica desconsidera o tecido social e cultural da surdez ${ }^{(24)}$. Assim, mesmo havendo esforços para efetivação do cuidado, evidenciam-se o despreparo do profissional e o desconforto mútuo no atendimento às pessoas surdas, comprometendo sua assistência, porquanto os surdos não são compreendidos de maneira plena em suas necessidades.

"[...] parece que o profissional ficou nervoso. Como é que ele ia tentar se comunicar com o surdo ali naquele momento? Eu fiquei esperando qual seria a reação desse médico. Vamos escrever, escrevemos, e o médico ficou assim todo errado e mostrava a escrita e eu entendi 'corpo, corpo, está sentindo dor', ai ele escrevia e eu ficava pesando como seria a palavra que ele ia colocar. Aí eu percebia que o médico estava suando, porque não estava conseguindo se comunicar, e foi a coisa mais difícil da minha vida. Quando ele escrevia uma palavra, eu não entendia, teria que realmente esse médico ter pelo menos um básico para poder ter uma comunicação básica"(S7).

Sentimentos diversos, dentre os quais angústia, medo, insegurança e impaciência, sucedem no ato da consulta, e, por vezes, se manifestam em decorrência do despreparo dos profissionais para lidarem com essa clientela ${ }^{(17,25)}$. Ademais, quanto mais longe estão os profissionais de saúde do universo de seus usuários, ou seja, quanto menos sabem realmente a respeito deles, maiores são os desconfortos quando lidam com essas pessoas. O referente às suas particularidades transpostas ao déficit sensorial impossibilita uma aproximação com esse outro com origem noutras dimensões - culturais, simbólicas, sociais - importantes para o cuidado.

No Brasil, visando romper com as barreiras atitudinais, de comunicação e informação, bem como a viabilizar a assistência aos surdos nos serviços de saúdeforam publicados leis e decretos nessa área nos últimos anos, o que representou para a comunidade surda importante avanço na sua inclusão social. Ao prever a Libras como disciplina curricular obrigatória nos cursos de formação dos professores para o magistério, no curso de Fonoaudiologia e em outros cursos de maneira optativa, o Decreto 5.626/2005, que regulamenta a Língua Brasileira de Sinais como código para comunicação e expressão da comunidade de pessoas surdas, tende a induzir à formação de profissionais para atendimento desse contingente ${ }^{(26)}$. O dispositivo incentiva ainda a capacitação e formação de profissionais que atuem na rede do Sistema Único de Saúde (SUS) para uso da Libras e sua tradução e interpretação.

Após dez anos de publicação do retromencionado dispositivo legal, verifica-se, na prática, a inclusão da disciplina Libras no currículo dos cursos de graduação e um aumento na oferta de cursos de Libras nas modalidades extensão e formação, tanto por empresas privadas como pelo serviço público, contribuindo para formar, ou ao menos sensibilizar, os profissionais de saúde e habilitar profissionais intérpretes.

Embora os surdos reconheçam o aumento de profissionais habilitados para interpretação da língua de sinais, a ausência de intérprete nos pontos de atenção constitui obstáculo à assistência, ferindo o direito constitucional à saúde. Cabe ao Estado, de acordo com a Constituição Cidadã, a proteção à saúde de todos os cidadãos, possibilitando, dentre outras ações, o acesso justo e igualitário ao conjunto de ações e serviços ofertados pelo Sistema Único de Saúde (SUS):

"[...] Antes era bem pior. Hoje em dia melhorou, não muito, vamos botar quarenta por cento. [...] No passado, era só com a família junto. |Não tínhamos intérprete, era muita mímica. E, hoje em dia, não. O número de intérprete aumentou, então a gente vai ao médico [...] temos intérprete para ir junto, melhorou muito, o problema é que nós é que temos que pagar [...] mas mesmo assim a acessibilidade para gente falta muito [...] Falta incentivo do governo para custear os intérpretes." (S1).

\section{Atitudes para minimizar as barreiras de comunicação}

Malgrado as conquistas alcançadas via dispositivos legais, os surdos ainda são responsáveis por solucionar, ou minimizar, as barreiras de comunicação e informação no encontro clínico com os profissionais ouvintes. Em razão da reduzida possibilidade 
do diálogo, na maioria das vezes, buscam os serviços acompanhados de um membro familiar ou amigo, necessitando de uma terceira pessoa para intermediar a consulta ${ }^{(21)}$. Queixam-se, no entanto, de que, na companhia deste, dados importantes lhe são transmitidos de maneira parcial, sendo privados de informações acerca de sua condição de saúde/doença, o que, de algum modo, fere sua autonomia.

\begin{abstract}
"[...] minha mãe e eu fomos ao ginecologista e me perguntava uma coisa e eu falava para minha mãe que entendia mais ou menos. Ela dizia que estava tudo normal, tudo normal, mas assim, eu não compreendia o que eu estava sentindo [...] no hospital, eu não tenho coragem de ir sozinha" (S11).
\end{abstract}

"[...] eu compreendo quando minha sogra conversa comigo, agora minha mãe não. A minha mãe fala mais com o médico do que comigo. Eu fui várias vezes com ela e não consegui compreender”(S7).

Embora o acompanhante-ouvinte auxilie no atendimento, em alguns casos, pode representar um problema: quando limita o surdo de protagonizar o próprio cuidado e de tomar as decisões pertinentes a sua saúde, manifestando, no ato da consulta, atitude de passividade ${ }^{(27-29)}$. Por não compreender seu papel de mediador na comunicação entre o surdo e o profissional de saúde, o ente familiar, embora tente ajudar, invade o espaço da consulta, interferindo na relação entre ambos. No exercício de sua autonomia e em busca do entendimento pleno da consulta, aqueles que podem pagar recorrem ao serviço particular de interpretação, embora essa seja uma opção somente para alguns. Os surdos participantes da presente pesquisa, por utilizarem a Libras como primeira língua, apontam o uso dessa modalidade comunicativa no ato da consulta como primordial para se sentirem compreendidos. Essa realidade também foi observada em outros estudos, cujas pesquisas foram realizadas com surdos que se comunicam por língua de sinais ${ }^{(29,30)}$. Em face, porém, do despreparo do profissional ouvinte para lidar com essa clientela, ou mesmo da ausência de intérpretes nos serviços, surdos e profissionais recorrem a distintos recursos comunicativos, inclusive à escrita, a fim de viabilizar o atendimento. Os surdos reconhecem, no entanto, dificuldades de compreensão do português escrito:

“[...] levei uma queda e quero explicar o que aconteceu, como é que esse atendimento aí vai me ajudar se eu não estou
nem compreendendo? A dificuldade é essa. Ass vezes me utilizo de mímica para me comunicar”(S7).
“[...] resolvi ir sozinho ao médico, mostrei onde eu estava sentindo dor [...] levantei a camisa e mostrei para ele dizendo
'ó ta doente aqui', aí ele foi e apertou, olhou, aí perguntou 'você come o quê?’'Aí deu uma entrevista, assim, bem na
mímica, e escreveu. Só que quando escreve a gente não entende. Têm muitas letras e eu não conseguia entender [...]
Então a gente pega, bota o número do telefone ai liga, e pede que passe a informação para algum familiar ou intérprete,
e eles passam para gente. Vamos supor, a prescrição médica. Eu dou o telefone, ou alguém me liga, aí explica qual o
horário e o medicamento que tem que tomar, aí o chato é essas coisas, entendeu? Que a gente ainda depende disso” (S1).

Mímicas e gestos são sinais não verbais valiosos, sendo utilizados corriqueiramente ante as dificuldades comunicativas que ocorrem no ato da consulta. Mensagens curtas são passíveis de compreensão pelo emprego desses recursos. De igual modo, é possível reconhecer sinais ditos universais, como expressão de dor, porém exigem esforços extraordinários para compreensão adequada e um maior tempo de consulta ${ }^{(27)}$. Em comunicação mais complexa, como quando se quer conhecer de modo ampliado a história do paciente, tais estratégias se mostram menos eficazes, aumentando a possibilidade de erros de interpretação da mensagem $^{(18,25)}$.

De efeito, o auxílio de terceiros (ente familiar ou intérprete) por via de telefone é uma estratégia possível, ante situaçõeslimite (explicação da prescrição medicamentosa, na tentativa de minimizar possíveis erros que comprometam sua saúde), embora interfiram na autonomia da pessoa surda. O emprego de termos técnicos e a escrita de modo ilegível dificultam ainda mais o reconhecimento da mensagem ${ }^{(27)}$. Caso o profissional utilize a escrita, convém fazer uso de letra legível e frases curtas, simplificar termos e manter a calma durante a interação ${ }^{(31,32)}$. O recurso da escrita, embora valorizado pelos profissionais ouvintes $^{(32)}$, pode ser um impeditivo quando utilizado como recurso único, sobretudo com surdos que tenham pouca compreensão do português escrito. $\mathrm{O}$ uso da escrita foi apontado como uma das estratégias comunicativas que dificulta o acesso do surdo ao serviço de saúde, no entanto esse é um dos recursos mais utilizados pelos profissionais em interação com os surdos ${ }^{(21,30)}$. Para muitos surdos, a língua portuguesa escrita é segunda língua, podendo haver dificuldades em seu domínio ${ }^{(33)}$, ao passo que eles também enfrentam dificuldade de acesso ao sistema educacional.

Compreender que os surdos se comunicam de várias maneiras é romper com a visão de homogeneidade do universo da surdez. Há surdos que se comunicam pela língua de sinais; outros, pela fala. Alguns se utilizam da leitura labial; outros se comunicam por meio da escrita, outros apenas por gestos, e há ainda os que fazem uso de mais de uma modalidade de comunicação. No estudo sob relatório, todos os surdos se comunicavam pela língua de sinais, mas alguns realizavam a leitura labial, outros utilizavam a modalidade escrita do português e alguns oralizavam algumas palavras. Variadas estratégias podem ser utilizadas no encontro entre surdos e profissionais de saúde. Cabe a eles escolherem as estratégias comunicacionais que possibilitam melhor compreensão e facilitam o acesso ao cuidado ${ }^{(17)}$. Uma vez que os profissionais estejam capacitados nessas habilidades, promoverá mais facilidade na interação, sendo reduzidas possíveis barreiras. Conhecer as estratégias para comunicação com as pessoas surdas, bem como as limitações para seu uso, ajuda a orientar os profissionais de saúde no trato para com elas, e, de igual modo, auxilia o gestor a organizar os serviços com base nas necessidades desses usuários. 
Estratégias simples, como um painel visual no serviço com a entrega de senhas e a comunicação entre a recepção e os profissionais avisando que o surdo está na sala de espera, são de grande valia para viabilizar o acesso aos serviços ${ }^{(31)}$. A seguir serão expostas sugestões para assistência à pessoa surda, que podem ser adotadas nos pontos de atenção da Rede de Cuidados à Pessoa com Deficiência.

\section{Sugestões para melhoria da assistência nos serviços de saúde}

Os surdos participantes do presente estudo não encaram as dificuldades de assistência à saúde com resignação. Ao contrário disso, fazem proposições e atribuem ao Governo o papel de incentivar e propiciar a acessibilidade. Uma das proposições é o emprego da língua de sinais nos pontos de atenção da rede, seja pela inserção de intérpretes de língua de sinais, seja pelo uso da língua por profissionais capacitados. Sugerem que o Governo invista na formação dos profissionais da saúde para habilitá-los na aplicação dessa modalidade comunicativa. Apontam, contudo, que o aprendizado de Libras por ouvintes só ocorrerá, de fato, se houver contato permanente com a língua. Após capacitados, muitos ouvintes esquecem os sinais. Recomendou-se, pois, a inclusão do surdo, ou do intérprete de língua de sinais, nos serviços de saúde, para que haja interação contínua em prol de uma comunicação efetiva.

"No [...] [um serviço de saúde] funcionários de lá já vieram fazer o curso, só que a gente chega lá para atendimento e eles esqueceram, eles não sabem nem conversar com a gente, eles não conseguem interpretar, então a dificuldade maior é essa. [...] Precisava ter um interprete lá dentro, entendeu? Ou então colocar um surdo lá para estar ensinando os funcionários lá dentro, trabalhar direto lá dentro, estar ensinando os funcionários que já fizeram o curso, estar lá o tempo todo para conviver com eles” (S2).

Quanto ao trabalho profissional do intérprete de língua de sinais nos serviços de saúde, os surdos reconhecem e valorizam sua importância para mediar a comunicação, propondo um modo de organizar sua disponibilidade. Em meio ao regime de chamada, intérpretes, custeados pelo Governo, seriam acionados para realizar a interpretação, caso o serviço de saúde não dispusesse do profissional. Em 2014, os municípios de Juazeiro do Norte e Fortaleza passaram a dispor de Centrais de Interpretação de Libras para atendimento aos surdos. De igual modo, em 2016, a Coordenadoria Especial de Políticas Públicas para Pessoa Idosa e Pessoa com Deficiência, órgão estadual, também inaugurou uma central. De acordo com o Ministério Público do Estado do Ceará, em 2016, as duas centrais municipais exprimiram dificuldades em prover o atendimento necessário à pessoa surda em razão do número reduzido de intérpretes contratados ${ }^{(34,35)}$. Iniciativa similar foi realizada em outro estado brasileiro, expressando-se como fato recente na história de inclusão social da pessoa surda ${ }^{(21)}$.

Conquanto sejam requeridos intérpretes nos serviços de saúde, alguns surdos veem com reserva esse profissional no momento da consulta para assuntos íntimos, mostrando-se como importante ponto a ser investigado:

"Eu sonho assim, que o governo pague um intérprete para ficar o tempo todo em um hospital, ou em outro lugar. Porque, às vezes, não temos condições de pagar. Vamos supor, uma associação ter três intérpretes disponíveis pagos pelo governo e qualquer surdo, ao precisar, e se não tivesse intérprete no local do atendimento, pode ligar e chamar o intérprete na hora, assim resolveria o problema” (S2).

"[...] tem algumas coisas particulares que infelizmente você fica com vergonha de levar um intérprete. Então, se for uma coisa muito particular sua, você pode pedir à família para ir como você, para escrever, mas se for uma coisa assim, você pode ir com o intérprete" (S1).

Alguns surdos demonstram desconforto em compartilhar assuntos na presença do intérprete. Desse modo, para assuntos mais reservados, preferem ser atendidos apenas pelo próprio profissional de saúde que utilize língua de sinais ${ }^{(2,31,33)}$.

No Brasil, estudos sobre interpretação no contexto médico são praticamente inexistentes, não havendo ainda a interpretação médica como ocupação institucionalizada. Embora haja crescente demanda por serviço de interpretação no âmbito do serviço de saúde, não existem cursos específicos para habilitar profissionais na área ${ }^{(36)}$. As políticas linguísticas e de acesso fomentadas no Brasil nos últimos anos revelam uma perspectiva para tradução e interpretação de língua de sinais nos serviços de saúde. Nesse sentido, a inserção do intérprete necessita ser discutida, uma vez que as competências e habilidades necessárias para atuar nos serviços de saúde envolvem, além do rigor técnico para tradução e interpretação da Libras em língua portuguesa e viceversa, as questões éticas de sigilo e imparcialidade das informações, bem como o conhecimento requerido na área da saúde para entendimento e interpretação da mensagem nesse contexto. Assim, deve conhecer, além de termos técnicos específicos da área, o modo de se portar nesse espaço, as questões éticas voltadas para a saúde e a doença exigidas na situação.

Ressalta-se a importância do desenvolvimento de pesquisa na área e da criação de currículos para formação de profissionais intérpretes, com vistas a estruturar esse campo de atuação e a formar intérpretes qualificados para o atendimento na área da saúde ${ }^{(36)}$. Almeja-se que os cursos ofertados para a formação de tradutor intérprete da Língua Brasileira de Sinais desenvolvam nesses profissionais as competências e habilidades necessárias para atuar nos serviços de saúde, bem como uma atitude ética e de responsabilidade profissional, preceitos primordiais para sua atuação, conforme preconiza a lei que regulamenta a profissão ${ }^{(37)}$. 
Para os surdos conviverem em seu universo, traz a exigência de uma mudança de paradigma, que se efetiva no respeito às diferenças ${ }^{(33)}$. A implantação de uma rede de atenção pautada nos princípios do cuidado integral e humanizado não se efetiva se não houver escuta, vínculo e diálogo entre os que buscam a assistência e os prestadores de cuidado. A língua de sinais, na perspectiva desses surdos, é o mecanismo que viabiliza essa troca e o êxito de suas demandas. Desse modo, seu emprego deve ser incentivado nos pontos de atenção da rede para o acesso às ações de saúde.

A Atenção Primária à Saúde (APS), como o nível de atenção mais próximo dos usuários, exerce importante papel no acesso aos serviços e na resolubilidade dos problemas de saúde. Há evidências, contudo, de que o nível primário não está organizado para satisfazer suas necessidades, porquanto o estudo aponta que os surdos utilizam mais os hospitais e os serviços distantes de sua residência ${ }^{(38)}$.

A APS, como um dos componentes da Rede de Cuidados à Pessoa com Deficiência, deve se organizar para garantir o atendimento às pessoas surdas nas unidades básicas de saúde. As equipes de Saúde da Família, apoiadas pelos profissionais do Núcleo de Apoio à Saúde da Família (NASF), podem dimensionar o quantitativo de pessoas com surdez e suas necessidades de saúde, conhecer os riscos e vulnerabilidades aos quais estão expostos, e viabilizar a continuidade do cuidado na rede.

De acordo com a portaria que regulamenta a $\mathrm{RCPD}^{(1)}$, pode-se ainda realizar cuidados nos domicílios, incentivar a inclusão e a qualidade de vida por meio de recursos da comunidade, e elaborar linhas de cuidados que possam orientar a atenção à saúde das pessoas surdas. O CER, embora reconhecido na portaria como instrumento político-institucional para sua regulamentação, mostra-se frágil quanto a sua implantação em decorrência ao elevado custo para construção e custeio. Outros equipamentos, já edificados, podem fazer parte da rede, sendo lócus de atenção a essas pessoas.

\section{CONSIDERAÇÕES FINAIS}

O estudo ora findo possibilitou conhecer as peculiaridades da assistência à saúde às pessoas surdas, usuárias de língua de sinais, a partir da sua perspectiva, com vistas a refletir sobre o acesso, o cuidado humanizado e integral, e o direito à saúde ante a proposta de implantação da Rede de Cuidados à Pessoa com Deficiência.

As barreiras de comunicação e informação durante o atendimento dos surdos revelam o desafio para uma assistência humanizada e integral em virtude de uma comunicação restrita. Acredita-se que a língua de sinais é um dos caminhos para uma efetiva comunicação com esses usuários nos serviços de saúde. Embora o intérprete de língua de sinais não seja decisivo para garantir um atendimento de qualidade, pode melhorar substancialmente, quando bem preparado, com habilidades e competências necessárias para atuar nesse espaço.

Deve-se, então, investir na formação de intérprete de língua de sinais, para atuar nos diversos pontos da rede de atenção e, de igual modo, incentivar a formação de profissionais de saúde que já atuam na rede SUS. Essas estratégias, aliadas ao investimento na formação do profissional de saúde, ainda na graduação, com foco na humanização, na ética, nas especificidades orgânicas, linguísticas e culturais das pessoas com surdez, bem como nas técnicas que podem facilitar a interação de profissionais ouvintes e usuários surdos, são cruciais para viabilizar a qualidade das intervenções em saúde.

Na perspectiva desses informantes, os serviços de saúde ainda não se organizaram para atender suas necessidades. Embora reconheçam conquistas legais, ainda há desafios a serem superados, impostos, sobretudo, pelas barreiras atitudinais, de comunicação e informação ocorrentes na relação interpessoal, o que limita o exercício da autonomia e a liberdade de escolha, diretriz importante para funcionamento da Rede de Cuidados à Pessoa como Deficiência. Cabe aos gestores, profissionais de saúde, usuários e instituições formadoras, com suporte nas políticas indutoras e na realidade local, organizarem linhas de cuidados para atenção à saúde das pessoas surdas que considerem as particularidades reveladas e assegurem de modo efetivo o direito à saúde reconhecido na Constituição Cidadã.

\section{REFERÊNCIAS}

1. Brasil. Ministério da Saúde. Portaria n ${ }^{\circ} .4 .279$, de 30 de dezembro de 2010a. Estabelece diretrizes para organização da rede de atenção à saúde no âmbito do sistema único de saúde (SUS) [Internet] Diário Oficial da República Federativa do Brasil; Brasília; 2010 dez 31.

2. Brasil. Ministério da Saúde. Portaria $n^{\circ}$. 793, de 24 de abril de 2012. Institui a rede de cuidados à Pessoa com Deficiência no âmbito do sistema único de saúde [acesso em 2017 Maio 15]. Disponível em: http://bvsms.saude.gov.br/bvs/saudelegis/ gm/2012/prt0793_24_04_2012.html

3. Instituto Brasileiro de Geografia e Estatística - IBGE. Censo demográfico 2010: Características gerais da população, religião e pessoas com deficiências. Rio de Janeiro: IBGE; 2010.

4. Munguba MC, Vieira ACVC, Porto CMVP. Da invisibilidade à participação social: promoção da saúde em pessoas com deficiência. Rev Bras Promoç Saúde. 2015;28(4):463-6. 
5. Brasil. Decreto $n^{\circ} 7.612$, de 17 de novembro de 2011. Institui o Plano Nacional dos Direitos das Pessoas com DeficiênciasPlano Viver sem Limite. [Internet] Diário Oficial da República Federativa do Brasil, Brasília. 2011 Nov 18 [acesso em 2017 Maio 15]. Disponível em: http://www.planalto.gov.br/ccivil_03/_ato2011-2014/2011/decreto/d7612.htm

6. Secretaria de Saúde do Estado do Ceará. Plano Estadual de Estruturação da Rede de Cuidados à Pessoa com Deficiência no Ceará 2013-2016. 2013.

7. Brasil. Lei no 13.146 , de 06 de Julho de 2015. Institui a Lei Brasileira de Inclusão da Pessoa com Deficiência. [Internet] Diário Oficial [da] República Federativa do Brasil, Brasília. 2015 [acesso em 2017 Maio 15].

8. Bosi MLM, Mercado-Martinez FJ. Introdução: notas para um debate. In: 2. ed. Petrópolis: Vozes; 2007; 23-71.

9. Minayo MC. O desafio do conhecimento: pesquisa qualitativa em saúde. 14. ed. São Paulo: Hucitec/Abrasco; 2014.

10. Haguette TMF. A entrevista. In: Metodologias qualitativas. 7 ed. Petrópolis: Editora vozes; 2007; 86.

11. Minayo MCS, Suely FD, Gomes R. Pesquisa social: método e criatividade. 29. ed. Petrópolis: Editora vozes; 2010; 107.

12. Conselho Nacional de Saúde (BR). Resolução n ${ }^{\circ}$ 196, de 10 de outubro de 1996. Dispõe diretrizes e normas regulamentadoras de pesquisa envolvendo seres humanos. Bioética.1996; 4 (2Supl):15-25.

13. Brasil. Ministério da Saúde. Conselho Nacional de Saúde. Resolução no. 466, de 12 de dezembro de 2012. Dispõe diretrizes e normas regulamentadoras de pesquisa envolvendo seres humanos [internet]. [acesso em 2017 Maio 15]. Disponível em: http://bvsms.saude.gov.br/bvs/saudelegis/cns/2013/res0466_12_122012.html

14. Chaveiro N, Barbosa MA, Porto CC, Munari DB, Medeiros M, Duarte SBR. Atendimento à pessoa surda que utiliza a língua de sinais na perspectiva do profissional da saúde. Cogitare Enferm. 2010;15(4):639-45.

15. Schwartz MA. Deaf patients, doctors, and the law: compelling a conversation about communication. Florida State University Law Review. 2008;35(4):947-1002.

16. Richardson KJ. Deaf culture. Nurse Pract. 2014;39(5):20-8.

17. Miranda RS, Shubert CO, Machado WCA. A comunicação com pessoas com deficiência auditiva: uma revisão integrativa. Rev. pesqui. cuid. fundam. (Online). 2014;6(4):1695-706.

18. Pagliuca LMF, Fiuza NLG, Rebouças CBA. Aspectos da comunicação da enfermeira com o deficiente auditivo.Rev Esc Enferm. 2007;41(3):411-8.

19. Kritzinger J., Schneider M, Swartz L, Braathen, SH. "I just answer 'yes' to everything they say”: access to health care for deaf people in Worcester, South Africa and the politics of exclusion. Patient Educ Couns. 2014;94(3):379-83.

20. Barnett S. Communication with deaf and hard-of-hearing people: guide for medical education. Acad Med. 2002;77(7):694700 .

21. Pires HF, Almeida MAPT. A percepção do surdo sobre o atendimento nos serviços de saúde. Rev Enferm Contemporânea. 2016;5(1):68-77.

22. Nobrega JD, Andrade AB, Pontes RJP, Bosi MLM, Machado MMT. Identidade surda e intervenções em saúde na perspectiva de uma comunidade usuária de língua de sinais. Ciênc Saúde Coletiva 2012;17(3):671-9.

23. Kuenburg A, Fellinger P, Fellinger J. Health care access among deaf people. J Deaf Stud Deaf Educ. 2015;21(1):1-10.

24. Gesser A. Do patológico ao cultural na surdez: para além de um e de outro ou para uma reflexão crítica dos paradigmas. Trab Linguist Apl 2008; 47(1):223-39

25. Sheppard K. Deaf adults and health care: Giving voice to their stories. J Am Assoc Nurse Pract. 2013;26(9):504-10.

26. Brasil. Decreto $n^{\circ}$. 5.626, de 22 de dezembro de 2005. Regulamenta as Leis $n^{\circ}$. 10.436, de 24 de abril de 2002, que dispõe sobre a língua brasileira de sinais - Libras, e o art. 18 da Lei no .10 .098 , de 19 de dezembro de 2000. Diário Oficial República Federativa do Brasil. 2005 dez. 22.

27. Cardoso AHA, Rodrigues KG, Bachion MM. Perception of person with severe or profund deafness about the communication process durong heatth care. Rev Latinoam Enferm. 2006;14(4):553-60.

28. Oliveira YCA, Coura AS, Costa GMC, França ISX.Comunicação entre profissionais de saúde-pessoas surdas: revisão integrativa. Rev Enferm UFPE Online. 2015;9(Supl 2): 957-64. 
29. Oliveira YCA, Celino SDM, Costa GMC. Comunicação como ferramenta essencial. Physis (Rio de J). 2015;25(1):307-20.

30. Nascimento GB, Fortes LO, Kessler TM. Estratégias de comunicação como dispositivo para o atendimento humanizado em saúde da pessoa surda. Saúde (Santa Maria). 2015;41(2):241-50.

31. Costa LSM, Almeida RCN, Mayworn MC, Alves PF, Bulhões PAM, Pinheiro VM. O atendimento em saúde através do olhar da pessoa surda: avaliação e propostas. Rev Bras Clin Med. 2009;7:166-70.

32. Tedesco JR, Junges JR. Desafios da prática do acolhimento de surdos na atenção primária. Cad Saúde Pública. 2013;29(8):1685-9.

33. Chaveiro N, Porto CC, Barbosa MA. Assistência ao surdo na área de saúde como fator de inclusão social. Rev Esc Enferm USP. 2005; 39(4):417-22.

34. Ministério dos Direitos Humanos (BR). Ministra inaugura central de Libras em Fortaleza, nesta segunda [acesso em 2016 Dez 21]. Disponível em: www.sdh.gov.br/noticias/2014/abril/ministra-inaugura-central-de-libras-em-fortaleza-nestasegunda-28

35. Ministério Público do Ceará. Audiência pública no MPCE debate Central de Intérpretes de Libras. 2016 [acesso em 2016 Dez 21]. Disponível em: www.mpce.mp.br/2016/04/07/audiencia-publica-no-mpce-debate-central-de-interpretes-delibras/

36. Queiroz M. Panorama da interpretação em contextos médicos no Brasil: Perspectivas. Trad Terminologia. 2014;23:193223.

37. Brasil. Presidência da República, Subchefia para Assuntos Jurídicos. Lei nº 12.319 , de $1^{\circ}$ setembro de 2010b. Regulamenta a profissão de Tradutor e Intérprete da Língua Brasileira de Sinais - Libras. Internet]. Brasília; 2010.

38. Freire DB, Gigante LP, Béria JU, Palazzo LS, Figueiredo ACL, Raymann BCW. Acesso de pessoas deficientes auditivas a serviços de saúde em cidade do Sul do Brasil. Cad Saúde Pública 2009;25(4):889-97.

\section{Endereço para correspondência:}

Juliana Donato Nóbrega

Universidade Federal do Ceará - UFC

Rua Professor Costa Mendes, 1608. Bloco Didático, $5^{\circ}$ andar.

Bairro: Rodolfo Teófilo.

CEP: 60.430-140- Fortaleza - CE - Brasil

E-mail: julianadonato7@yahoo.com.br 